\section{Public Health Genomics}

Public Health Genomics 2014;17:84-94

DOI: $10.1159 / 000357958$
Received: September 9, 2013

Accepted after revision: November 28, 2013

Published online: February 19, 2014

\title{
Community Engagement in US Biobanking: Multiplicity of Meaning and Method
}

\author{
K.M. Haldeman ${ }^{a}$ R.J. Cadigan ${ }^{a, b} \quad$ A. Davis ${ }^{a, b} \quad$ A. Goldenberg ${ }^{c}$ \\ G.E. Henderson ${ }^{a, b}$ D. Lassiter ${ }^{b} \quad$ E. Reavely ${ }^{b}$ \\ ${ }^{a}$ Department of Social Medicine, and ${ }^{b}$ Center for Genomics and Society, University of North Carolina, \\ Chapel Hill, N.C., and 'Department of Bioethics, School of Medicine, Case Western Reserve University, \\ Cleveland, Ohio, USA
}

\section{Key Words}

Biobanks · Community engagement $\cdot$ Ethical, legal and social issues - Qualitative methods

\begin{abstract}
Background/Aims: Efforts to improve individual and population health increasingly rely on large-scale collections of human biological specimens and associated data. Such collections or 'biobanks' are hailed as valuable resources for facilitating translational biomedical research. However, biobanks also raise important ethical considerations, such as whether, how and why biobanks might engage with those who contributed specimens. This paper examines perceptions and practices of community engagement (CE) among individuals who operate 6 diverse biobanks in the US. Methods: Twenty-four people from a diverse group of 6 biobanks were interviewed in-person or via telephone from March to July 2011. Interview transcripts were coded and analyzed for common themes. Results: Emergent themes include how biobank personnel understand 'community' and CE as it pertains to biobank operations, information regarding the diversity of practices of $\mathrm{CE}$, and the reasons why biobanks conduct CE. Conclusion: Despite recommendations from fed-
\end{abstract}

eral agencies to conduct $C E$, the interpretation of $C E$ varies widely among biobank employees, ultimately affecting how CE is practiced and what goals are achieved.

(c) 2014 S. Karger AG, Base

\section{Introduction}

The Centers for Disease Control and Prevention (CDC) has emphasized the importance of community engagement $(\mathrm{CE})$ in improving the public's health, and the quality and applicability of population research in general [1]. Over time, federal agencies such as the National Institutes of Health and the Agency for Healthcare Research and Quality have joined the CDC in emphasizing the benefits of CE, to '.. . build trust, enlist new resources and allies, create better communication and improve health outcomes' [1]. At the same time, efforts to improve individual and population health increasingly rely on large-scale collections of human biological specimens and associated data. Such collections or 'biobanks' comprise an emerging industry with a valuable resource for facilitating effective translational biomedical research. What is not clear, however, is whether biobanks respond

\section{KARGER}

E-Mail karger@karger.com

www.karger.com/phg (c) 2014 S. Karger AG, Base

$1662-4246 / 14 / 0172-0084 \$ 39.50 / 0$
Kaaren M. Haldeman, $\mathrm{PhD}, \mathrm{MPH}$

Department of Social Medicine, University of North Carolina

333 S. Columbia Street, MacNider Hall, Room 348/CB 7240

Chapel Hill, NC 27599-7240 (USA)

E-Mail kaaren@email.unc.edu 
to calls for $\mathrm{CE}$ and how and why they might engage in CE with those who contributed specimens and data as well as communities at large.

Biobanks are remarkably heterogeneous organizations [2] which vary in size, mission, acquisition of specimens, and population of contributors; they may be independent, commercial organizations, or embedded within academic institutions, hospitals, government programs, disease advocacy organizations, and more. Such differences are likely to have implications for how a biobank may approach the desirability, design and implementation of their CE efforts. Additionally, although the CDC, National Institutes of Health, Agency for Healthcare Research and Quality, and others emphasize the importance of $\mathrm{CE}$, no organization offers a set of guidelines for individuals or organizations endeavoring to conduct CE. Given this, we aimed to examine, using qualitative methods, the perceptions and practices of CE by a diverse group of biobanks.

\section{Origins of CE}

Although its origins date back to the 1940s in the work of educator and philosopher Paolo Freire, CE was not readily adopted in US health research until recent decades when it was first used to address population-level racialized and gendered health disparities $[1,3,4]$. It was heralded as an important approach to health problems that included the attitudes and beliefs of traditionally underor misrepresented subpopulations in the design and implementation of public health interventions. Community input was perceived as a way to avoid 'scientific racism' - or the use of scientific study to justify superiority of one 'race' over another - when attempting to study minority groups [5], while improving the success of public health interventions in health outcomes including heart disease, high blood pressure and preterm delivery, among others $[1,5,6]$. While CE was defined and operationalized differently in these studies, its perceived success meant that CE became an expected part of much public health intervention research.

The world of acronyms that emerged to identify models of CE reflects its definitional ambiguity. These frameworks include the best-known versions: CBPR (community-based participatory research) [7-9] as well as empowerment evaluation; participatory or community action research; participatory rapid appraisal [10]; CPPR (community-partnered participatory research) [11], CEnR (community-engaged research) [12]; and the framework favored by clinical researchers, PCI (patientcentered initiatives) [13]. These 'rhetorical cousins' [12]

Community Engagement in US

Biobanking appear to fall under the larger umbrella of CE, and it is often difficult to understand their differences. Thus, in both literature and in practice, many of these approaches appear to stand in for one another $[1,14]$.

In 1997, the CDC, along with the Agency for Toxic Substances and Disease Registry, published an initial handbook, 'Principles of Community Engagement'. With growing recognition by the clinical and translational sciences community that $\mathrm{CE}$ is an essential component of successful translation of medicine 'from bench to bedside to community', the Clinical and Translational Science Award's call for proposals in 2006 included a strong infrastructural component for CE. In 2011, the Clinical and Translational Science Award Consortium's Key Function Community Engagement Committee updated the 1997 handbook entitled 'Principles of Community Engagement' [1]. This most recent version notes that $\mathrm{CE}$ in health research is 'the process of working collaboratively with groups of people who are affiliated by geographic proximity, special interests, or similar situations with respect to issues affecting their well-being' and '.. is increasingly recognized as a vital component of efforts to expand access to quality care, prevent disease, and achieve health equity for all Americans' [1]. Active participation in CE, as described in the Principles of Community Engagement, refers to researcher and participant operating as 'partners' in research design, execution, analysis and dissemination of results. Its desired goals are to create and maintain long-term partnerships between researchers and the communities they serve in order to improve health equity and overall health and quality of life for all $[1,6,7,15]$. This definition of the overall goals of CE in translational research is echoed by Ross et al. [16], who also write that growing interest in CE is evidence of an '... emergent moral sensitivity of the research community to the value of engaging with the communities in which they seek to do research'. Overwhelmingly, public health practitioners and bioethicists perceive $\mathrm{CE}$ as a benefit for those engaging in research as well as the communities they serve $[7,14,15,17]$. Despite the growing recognition of CE as a vital paradigm in health research, according to some authors, its practices remain underdeveloped $[18,19]$, and as the CDC notes, '... the processes, costs and benefits of community engagement are still a relatively new field of study' [1].

The practice and implementation of community or public engagement activities in response to ethical, legal and social concerns regarding genetic information and research has received attention from authors examining large-scale prospective genetic studies, particularly the 
establishment and operation of national or other large genetic databases [20-24]. Some have delved more indepth into the meanings of 'participation' in an effort to better understand how community members act as participants in research studies and, thus, illuminate the kinds of engagement that are possible [23]. Tutton [23] examines participation in the context of citizenship and national genetic databases, hinting at a partnership model of engagement whereby 'people can participate in genetic databases not only as the sources of blood samples and data but also as potential co-decision makers'. Likewise, researchers engaged in large-scale genetic studies have explored the kinds of input and character of community-researcher interactions that long-term prospective studies may require [20-22]. While recognizing the value of ongoing communication with communities, they also note the complexity of such work, including increased cost, difficulties in practical implementation of activities, understanding its clear purpose, and a meaningful evaluation of such activities over time [22].

In the context of biobanking, Lemke et al. [19] explain the benefits of CE in terms of ethical behavior for research generally: 'Demonstrating respect for persons who volunteer to participate in research is an ethical good in itself. Moreover, by taking the initiative to engage their respective communities, researchers lay the groundwork to foster mutual understanding and trust, encourage public interest and participation in research, and potentially enhance the impact of their studies'. They describe CE as 'an important step in ensuring that biobank research is carried out in an ethical, locally appropriate manner, including a spectrum of community involvement used to inform, consult, involve, collaborate with or empower communities' [19]. Others have noted that purposes of CE include establishing trust in a biobank [25], guarding against a loss of trust in science [26] or to enhance the professionalization of biobanks [24].

As part of a large population-based biobank, McCarty and colleagues $[20,27]$ draw a stark contrast between their work involving ongoing, bi-directional flow of dialogue and ideas with community members and one-way engagement efforts aimed at informing a public and eliciting information from them [28]. In their examination of human tissue banking in B.C., Canada, O’Doherty and Hawkins [26] specifically address the lack of information regarding the translation of such dialogue into policy.

Lemke et al. [19] call attention to the need for more literature on approaches to CE specifically tailored to biobanks and their participants. Our study of 6 US biobanks addresses this gap in the literature, using qualitative in- terviews to explore how biobanking personnel understand community and CE, and how those understandings translate into practice. We argue that despite recommendations from federal agencies to conduct $\mathrm{CE}$, its meaning is widely interpreted among biobank employees, thus, affecting how its goals are perceived and ultimately how it is practiced.

\section{Materials and Methods}

\section{Study Background}

The larger study from which these interviews are taken is a mixed-methods project including case studies of 6 biobanks, with data drawn from qualitative interviews and document analysis, and an online national survey of 456 biobanks in the US [2, 29]. We designed the case studies of biobanks to be an exploratory study that would ultimately inform the design of our national survey. The 6 cases were chosen based on their sample procurement methods: de novo - human biological samples newly obtained from participants for future research, repurposed - human biological samples obtained from leftover specimens collected for clinical or public health purposes, and networked - human biological samples obtained through channels of networked banks. Ultimately, we discovered that sample procurement method was not an analytically valuable way to examine our data, so we do not highlight it in our results below. We have named the 6 biobanks: community, national, hospital, state, advocacy, and disease-focused. A description of these 6 biobanks can be found in table 1 .

\section{Interviews and Analysis}

Biobank personnel who fit one of several predetermined roles were interviewed for this study. Although these roles were loosely defined and often challenged in the study recruitment process, they were useful starting points for selecting respondents. The roles include: Principal Investigator, Study Coordinator, Information Technician, Institutional Review Board member, and Public Relations officer. Our qualitative research team of 4 social scientists collaboratively developed interview questions over the course of 3 months and presented each version of the interview guide to the larger multidisciplinary biobank study group for feedback. Interview topics included the history and mission of the biobank, its structure, policies and practices regarding certain ethical, legal and social issues of biobanking such as ownership of the specimens and informed consent procedures, and the biobank's relationships with the researchers who use the specimens (see table 2 for representative questions from each topic). Importantly for this analysis, we also asked many questions about the biobank's relationships with the community of potential and actual specimen contributors (referred to below as participants [23]). Some questions were asked to all interviewees, others were developed specifically for each biobank personnel role. All interviewees were recruited to participate in the interview as representatives of their particular biobank, and the vast majority of questions did not solicit individuals' opinions; however, some interviewees offered their personal opinions about different topics at different points throughout the interview.

From March through July 2011, we conducted semistructured interviews with a total of 24 biobank personnel, either in-person
Haldeman/Cadigan/Davis/Goldenberg/ Henderson/Lassiter/Reavely 
Table 1. Descriptions of the types of biobanks that participated in this study

\section{De novo Biobanks}

Community Biobank exists as part of a university but operates over 100 miles from campus in a small town setting. It originated by way of a very large philanthropic donation from one individual and its aim is to collect specimens from all residents of a particular geographic area. Healthy individuals are recruited at a variety of community-based events and doctor's visits.

National Biobank is funded by a national governing body and recruits healthy participants within one state's geographic limits. National Biobank collaborates with a local university in its sample collection. Participants were initially recruited in family-practice settings using leftover specimens, but in 2006, recruitment shifted to actively requesting samples from healthy participants.

\section{Repurposed Biobanks}

Hospital Biobank is housed within a large university and acquires both healthy and nonhealthy volunteers from opportunistic hospital and university employee populations and maintains an opt-out format for consent. Specimens collected for other clinical reasons are repurposed for use in this biobank.

State Biobank is a state-run biobank that, through an opt-in consent process, collects leftover dried bloodspots originally collected for newborn screening. This large biobank aims to make use of these specimens for a wide variety of medical and public health research efforts.

\section{Networked Biobanks}

Advocacy Biobank is a consortium of advocacy-based, disease-focused organizations that stores samples in one repository for use by researchers worldwide.

Disease-Focused Biobank is part of a research network of academic institutions that specifically collect specimens from hospital populations of patients with HIV/AIDS. We interviewed biobank employees from each of 2 universities in the network. Disease-Focused Biobank specimens are shared with the larger network to advance HIV research.

Table 2. Interview topics and sample questions

Mission

- What is the mission of the bank?

- What are the bank's current short-term goals?

- What are the bank's current long-term goals?

Structure

- Are there any internal conflicts/tensions within the bank's structure?

- What do you think are some of the risks of running the biobank?

- Thinking about the various divisions or branches [of the bank] how do you think the mission of [the bank] has influenced the way that it is structured?

Work/technology

- Are there particular ethical considerations that arise in collecting and storing these types of specimens?

- Thinking about the information [the bank] collects from people who contribute specimens, what do you see as the benefits and risks of collecting, storing, and updating this information?

- Are the specimens and data linked to the people who donate specimens? How? What do you call the people who contribute specimens?

Members

- I understand there are (\#) branches in [the bank]. What are the responsibilities of the different branches?

- How has [the bank] changed over time in terms of numbers of employees and their roles?

- How much turnover is there with employees? To what do you attribute the turnover?

Environment

- How do potential contributors hear about [the bank]?

- Does the bank maintain communication with its [specimen contributors]? How?

- What does the term 'community engagement' mean to you? 
or by telephone. Interviews averaged about $60 \mathrm{~min}$. We present here responses to interview questions regarding biobank interactions with specimen contributors, probing for specific efforts that were considered part of CE.

All interviews were digitally recorded and transcribed verbatim. We used qualitative analysis software NVivo $9.0^{\mathrm{TM}}$ to collect and analyze interview data. Using discussions with the larger research group, close readings of interviews, and conversations among our team, we developed a codebook with specific attention to sample procurement methods; organizational features; key ethical, legal and social issues; and other themes of interest that emerged from the full set of interviews. All coding was carried out by 4 individuals on the qualitative team. Coding validity was ensured by multiple coders analyzing a sample of interviews followed by discussion until consensus around coding and strategies was reached. Changes to the codebook were made collaboratively by all members of the qualitative research team.

We analyzed the interviews through close readings of full transcripts and generating reports (using NVivo 9. ${ }^{\mathrm{TM}}$ ) from specific codes that reflected themes of interest (e.g. community, CE and trust). Summaries of codes of interest and overall written summaries of findings for each biobank were provided to the larger research group. Members of the qualitative team then met several times for discussion of patterns and findings from each case and from the 6 biobanks as a whole. Results below are presented for biobanks identified by pseudonyms that provide general information about the bank's organizational form (table 1).

\section{Results}

Three themes emerged from our interviews with biobank personnel who fit one of the above-mentioned roles. Themes included: how respondents understood community and CE, how people who work for biobanks practice $\mathrm{CE}$, and why biobanks conduct $\mathrm{CE}$.

\section{How Biobanks Understand Community and CE}

Our interviews revealed that definitions of community and CE varied across the biobanks and even across respondents within the same biobank. First, we'll discuss understandings of community. Community was seen both as monolithic and as comprised of different components. Some respondents indicated a broader sense of community as a large population from which to collect samples, while others viewed community as a specific subset of larger populations, such as a hospital-based or disease-focused community. Still others considered research and scientific communities in their explanations. One respondent explained that a community consists of individuals and groups: 'Well, I think there's different levels. You know certainly the ... individuals who are in it - they make up a community, but then there's also the ... more formal groups that might exist within a commu- nity.' Another respondent referred to the community in more monolithic terms: '... the project leader established a community advisory board which is another advisory board soliciting input from community leaders who aren't necessarily within the health care or research field, but also nonetheless they're leaders in the community and sort of have their finger on the pulse of the community at large.'

Another interviewee from a community biobank also referred to community in terms of group and individual characteristics. She explained CE as a 2-way form of communication with multiple types of potential participants, stressing its reciprocal nature.

I interpret it literally. I mean that we are not thinking of them as a research population. That we are engaging them. It's participatory. They get an opportunity to have a voice in how the research is done, what research is done. They are - the communication is two way. We're not taking things from them, data and samples, and leaving them on their own. We are continually re-engaging them and identifying their needs and trying to meet them. We think of the community as all sorts of sub-communities. I mean a population is a population. It's also churches, networks, schools, families, employers. And so there - we engage them. It's about it's about bidirectional communication I think. Hearing them.

In addition to understanding community in a variety of ways, respondents' views of CE varied. For some biobanking personnel, CE was used as an educational tool, a guideline for communication with participants, and a way to stay informed about the needs, concerns and opinions of potential participants.

A respondent from a hospital biobank remarked that $\mathrm{CE}$ was intentionally built into the structure of the biobank, with the creation of specific plans, boards and oversight by bioethics experts. Interestingly, his overall understanding of the goal of $\mathrm{CE}$ is about changing or monitoring the attitudes of the local patient community about the biobank rather than engaging individuals as participants.

We have a very large community engagement element. And so it includes a specific community engagement plan that is monitored by the bioethics committee, has the formally constituted community advisory board that meets on a regular basis at least three times a year. It has a continuing review about whether the changing expectations for genetic research in the community are changing the ... community view of [us].

In this way, CE involves a one-way process of monitoring the community to ensure that their (currently positive) view of the biobank is not changing. Another view situated CE similarly, with information about the biobank flowing into its targeted community as a means of educating the people being recruited into the biobank. A 
respondent from a state biobank described it as a process aimed at research consent:

... we've done some presentations to groups like that ... certainly our initial big push has been more educating about the consent process that was being implemented and trying to get to prospective parents because at this point it's the most relevant for them to be informed so they can make their decision.

Another interviewee viewed CE 'in other studies' as a way to ask community members to help recruit new participants, but in her national biobank, CE was used as a tool for both recruitment and education:

... we don't do community engagement where we actually go to community groups and tell them you know 'Hey. Help us recruit here.' Or 'Help us you know advertise the study to your community.' And things like that like you would for community engagement in other studies, but we do go out into communities. ... we go to community groups for recruitment. We go to churches ... we've gone to street fairs and things like that. So we actually do go out into the community to recruit, and at the same time we hope that we're sort of educating them a little bit about these types of studies, biobanks and genetic studies and things like that.

With no clear definition of community, as 'levels', 'subcommunities' and interstitial 'leaders' abound, it is not surprising that respondents have different ideas of what constitutes CE. Most, however, seemed to believe it involved an element of education, especially as it relates to recruitment and enrollment of potential participants.

\section{How Biobanks Conduct CE}

Beyond understanding the meanings of $\mathrm{CE}$ for these biobank personnel, our aim was to understand the processes that comprised CE efforts. Our findings reveal multiple ways of conducting $\mathrm{CE}$ which, like conceptions of CE discussed in the previous section, involve both unidirectional and bi-directional activities aimed to educate potential participants about the purpose and activities of the biobank.

One interviewee from a state biobank described CE in terms of community forums the biobank orchestrated for the public, noting the forums failed as isolated ('standalone') events because of lack of attendance:

We did actually try holding a couple just community information forums, but they were not successful as a standalone kind of thing. ... we tried to hold one [in town] where we just invited anybody who wanted to learn about it to come, and I think we had some of our health department staff show up.... We had two other people. We had a member of our (community advisory board) who wanted to just come and see what we were doing, and then the other person ... was a parent, but he was mainly there because he was also a researcher, and he wanted to find out how to use the samples in his research ...

Community Engagement in US

Biobanking
This respondent perceived that this lack of participation reflected disinterest in the information, rather than as potentially linked to inadequate advertising or to lack of support for the biobank itself.

Finally, other respondents insisted they did not conduct CE formally, but spoke of it as an informal process. A representative from a state biobank suggested that CE involves delivering information to potential participants but considers anyone he may connect with as a potential recipient of his personal engagement efforts:

I consider it community engagement no matter who I'm speaking to ... I've been to conferences ... and I've spoken to groups of researchers. I went to Best Buy to make a purchase and filled out the tax exempt form, and out of curiosity the woman behind the counter said 'Huh. What is the State Biobank?' And I explained it to her. I consider that to be community engagement.

As noted by respondents above, some biobanks have established community advisory boards (CABs) as part of CE. When asked about the challenges and successes of the state biobank, a representative spoke about their CAB:

We now have the citizens' advisory group and with that well in place we were able to move forward with confidence that the citizens know or are well represented in making decisions about the [biobank]. So it was a challenge in that there was quite a bit of time involved and getting people up to speed, and forming the citizens' advisory board - that was the challenge. The success is that it's working, is that we truly have citizen involvement. This isn't in name only. It isn't a token position. ... This is real. These folks actually have a say in what goes on, and that's been our biggest success.

This interviewee's confidence in the success afforded by a 'real' citizen advisory group seems linked to the notion advanced by some proponents of CE that forming a $\mathrm{CAB}$ is an ethical activity because it means community members are 'well represented' in decision making. In fact, another representative from the state biobank noted that the way they engage ethics is through their CAB: '.. we have the community advisory board that can keep us on the straight and narrow with ethical issues.'

When asked about issues that biobankers felt were important to convey to potential participants, a representative of a community biobank referenced consent and the forms of CE aimed at information sharing and education:

I mean it's not just reading one consent form. We send newsletters. We have events. We do science fairs. We do lots and lots of community sort of education sessions in churches and schools and all over the place.

Although this person appeared interested in engagement efforts, she saw them as opportunities for one-way 
communication - from the biobank to potential participants in order to educate and inform.

A respondent from a state biobank talked about CE in terms of understanding public perceptions of the biobank via a direct gauge of its 'temperature'. He indicated that such engagement was designed to address public perceptions regarding the ethics of using stored specimens:

... the ethical issue was why don't we go take the temperature of some of the rest of the public to find out how they feel about it. So with very, very limited resources ... we started going hither and yon and talking to folks in focus group kinds of settings to find out what people thought about it, and in the main the results ... showed that the vast majority of people that we talked to were in fact thinking that this (using stored samples for research) was a good idea and not objectionable.

Interestingly, public responses that affirmed the use of stored specimens resulted in this respondent feeling as though the public supported the state biobank, which may or may not have been a correct assumption.

A respondent from a national biobank indicated that energy spent in attending a variety of community events was instrumental in increasing enrollment:

We went forward and just started going into the community, and we ended up going to things like the Dixie Gun and Knife Show, and the Septic Tank Association had a conference, and we went to that, and home and garden shows, just anything like that, and it was astounding how well we did with things like that. I'm just trying to think of some of the men's groups. We attended some of the African American male fraternity conferences and did great. ... I think as a whole we're higher than what we would have been had we stayed continually with the patient enrollment in the clinics.

A biannual newsletter was another CE platform for this biobank, as the interviewee explained:

... we just recently started doing a newsletter that's going out, and that's going out every six months ... That needed to happen from the beginning because ... seventeen thousand people I've come in contact with, and I run into some people who know us. They'll see ... the booth, and they'll be like 'Hey. So you know are you ... guys publishing any results? Are you doing anything?'

In this excerpt, the respondent highlights the newsletter as a way to give back to participants and also indicates, via the feedback he has received, that contributors hold the biobank to some level of accountability. He also appears to recognize the one-way nature of a newsletter, wishing for more interactive communication with participants. However, another employee of the same biobank noted that when personal contact is achieved in order to annually update contact information there may be unanticipated and undesirable outcomes for the biobank:
When we get into the phone call re-contacting, we have a spike in withdrawals because people are contacted directly, and it's easier for folks to say 'I'm not interested anymore.'

$\mathrm{CE}$, thus, becomes a double-edged sword whereby efforts at forming relationships with participants, although they may be valued, may become avenues for people to re-evaluate their participation in the study.

For the biobanks in our study, CE involves many different kinds of activities, some more interactive than others. Some biobanks have CABs whose purposes are to provide specific input to guide various stages of the biobanking enterprise. Some banks send newsletters to participants or publish their research findings in local papers. More active forms of engagement involve setting up focus groups, or talking with people at various community venues including fairs, churches and schools. These more active undertakings are usually intended to identify what may motivate participation or encourage people to enroll. Continued engagement after enrollment may remind them that contributors are expecting results and productivity, or may inadvertently 'backfire' when communication provides an easy mechanism for withdrawal. However, as we explore in the next section, many of our respondents discussed how processes of CE may create public support and trust in biobanking efforts.

\section{Why Biobanks Conduct CE}

Some of our interviewees perceived a close relationship with participants through $\mathrm{CE}$ and valued their relationships in interesting ways. One representative from a hospital biobank felt that procedures of engaging participants should include expressions of gratitude and promotion of a sense of sharing between researcher and participant:

I think the messages that we need to communicate to them are that this is an important foundation for research and that we appreciate their willingness to let us do this and that we need to share with them the kinds of things that we're learning ...

A state biobank employee values what she perceives as 'public support' in order to ensure biobank sustainability:

I think that the primary risk is not continuing to have public support. I mean you need public support in order for this to be sustainable to be successful. So I think while you're doing all these other things, coordinating the research, better preserving the specimens, garnering that interest in their use, you have to put as much emphasis and precedent on engaging and educating the community about what you're doing and making sure you're still continuing down a path that the public finds acceptable because things shift and change with time.
Haldeman/Cadigan/Davis/Goldenberg/ Henderson/Lassiter/Reavely 
Reconnecting with participants and receiving their feedback permits biobankers to understand how attitudes and beliefs about the bank change over time, ultimately enabling it to remain viable and, in this respondent's eyes, successful.

An employee of an advocacy biobank provided a relational understanding of CE that may be unique to advocacy contexts:

Some of them [other advocacy organizations] don't really even have the connections with their community. So I know they're not going to be successful. People donate to these because they have the relationship with the advocacy group. For the same reason people will participate in their physician's clinical trial. It's all relationship based.

She feels that CE ought to be about establishing relationships with your participants and that these relationships are necessary to succeed as a biobank.

For a representative from a community biobank, one of the greatest risks the biobank faces is losing or not gaining the trust of the local community. Her words indicate the amount of emotional energy spent on understanding local perceptions of genomic research and their biobank specifically:

I feel like the stakes are high. And so it's almost like the bar is higher because we had to go a long way to gain people's trust and to set the foundation. And so I worry that we don't have much room for human error because I feel like potentially the backlash could be great. ... I am very serious in communicating to the staff 'Folks, we need to do this right. We absolutely need to do it right.' ... We've worked really hard to get into this community, and this is their first experience with research.

Another employee from the same community biobank described its potential participants as a 'research naïve community' and explained CE efforts to establish trust through the work of 2 advisory boards:

This is a research naïve community. ... Really this community has no idea what research means. They don't even know what the word research means. So it's all about educating them about research in general, and then with that said what is a biobank? I mean that concept is sometimes hard to grasp ... it's very nebulous. You know we're going to take your blood and some information from you, and we don't know what we're going to do with it. And so educating them on what that is, what it means, why we need blood samples, what are we going to do with the blood samples.... so it's educating, and it's establishing trust. ... we have a health care advisory board and a community advisory board. So they are kind of our liaisons to the community and our advocates in the community.

Thus, the goal of establishing trust was seen as part of improving recruitment. Similarly, a respondent from a national biobank reports feeling a particular emotional closeness with some long-term participants - people she recruited and whose samples and recontact she handled:

... all the follow-up that we've had from people like in recontacting all the people, all the notes and things like that that we'd get back from people it seems like it's been very, very positive. I actually got a long note about a week ago from this woman ... telling me about her husband or somebody who had just died of a certain disease and saying how she's really grateful for studies out there. You know it had - the note was awful. I'll start crying if I think about it.

As indicated in the responses above, CE takes many forms with widely differing interpretations of value and meanings, applications in the biobanking research context, and goals and measures to reach them. While CE may be a way for biobankers to show appreciation to participants, they also seem to fear what might happen to the biobank if they fail to conduct CE. Fears included potential for difficulty in recruiting participants and whether or not the bank would secure funding and, thus, increase chances for sustainability. Therefore, they may view CE as a way to improve their research or to show appreciation to participants, yet their motivations may also come from fears of catastrophe - including closure of the biobank - should they fail to engender the community's trust and support.

\section{Discussion}

A great deal of attention has been paid to the idea of $\mathrm{CE}$ in a wide variety of fields, including biobanking $[1,4$, $7,13-15,19,30-32]$. Particularly in response to concerns about the inadequacy of informed consent for biobanking, a number of authors have argued that CE should be included as one component of a new and robust governance approach [33]. CE, in itself, is often seen as leading to better, more appropriate and effective research [1] the most positive rendition of the model aspires to create an egalitarian researcher-participant relationship, a partnership $[1,7]$. Despite these reported benefits of CE, no individual or organization has endeavored to provide guidance to biobanks as to what $\mathrm{CE}$ encompasses and how to achieve it. As the literature suggests and our research demonstrates, the ambiguity of the term has contributed to uncertainty as to what CE means, how it is performed and what it aims to achieve. Our findings reveal that this ambiguity leads to confusion about what it encompasses and whether it is successful in its efforts to partner with communities with the end result of enhancing the quality of biobanking research. 
Defining communities is a problematic process that has yet to be fully understood in the literature or in practice $[12,19,34,35]$. Following Weijer [36], Gbadegesin and Wendler [37] suggest that groups of people identified as communities have particular attributes when specifically participating in health research: '... common culture, political authority, shared resources, and self-identification as a community.' However, at least in the context of biobanking, our data demonstrate that meanings of community are far more complex. For biobankers, well-defined, circumscribed participant groups may or may not exist prior to banking efforts. If biobanks are established to contribute to research on a specific community, the target of $\mathrm{CE}$ is predefined. In other circumstances, potential biobank participants may share very few attributes. Associations with one another may be as loose as attending the same hospital one time or living in the same broad geographical area. This variation contributes to both the conceptual and practical confusions that confront biobankers as they attempt to engage 'their communities'.

Results of interviews from our biobank case studies also reveal different methods of engagement. These methods can vary both in depth and in duration. They may range from a single newsletter to a process of recontact or the development of a CAB. Among respondents in our study, the imperative to engage communities often translates into ideas about 'educating the community' in the hopes of, at best, enrolling participants, or at least, convincing community members of the value of the biobank so as not to oppose its practices. This motivation to sustain the biobank is understandable, but its link to 'education-focused' $\mathrm{CE}$ is problematic. Education becomes a delivery of information, making reciprocity (and the ability to derive information that informs the policies and practices of the bank) hard to discern.

Multiple views of both community and engagement are problematic for biobanks that are supposed to do CE in order to be more ethical in their practices and relationships. However, CE is interpreted; it can hold such sway that researchers interpret it as sufficient for the ethical conduct of research. In some cases, it seems to appear as a proxy for ethical practice itself, with its emphasis on respect for the voices and participation of participants. As Lemke et al. [19] note, '(F)rom an ethical standpoint, community engagement offers an opportunity to show respect for the individuals and communities involved in research and it may also be instrumental in preventing barriers to future research'. Outward measures of this respect vary greatly, however, and can reflect motivations compatible or incompatible with views of respect.
CABs are one approach used by researchers, including biobanks, to demonstrate respect (practice CE) [19, 25, 31]. However, a biobank's conceptualization of their participant 'community' may limit how well the participants who sit on the $\mathrm{CAB}$ represent the communities from which donors are recruited. When bank participants are drawn from very large and diverse populations within a hospital system or geographic area, it may be exceedingly difficult to adequately represent the various religious, cultural and ethnic groups that make up the communities from which donors are recruited. Even in cases where a community may be more defined and the members of a $\mathrm{CAB}$ are chosen carefully to be representative, it should not be assumed that this type of committee can account for the voices of all community members [38].

In a field as heterogeneous as biobanking, it is unlikely that specific engagement efforts will work equally well across all banks. As Newman [32] notes, these efforts both in conception and practice - deserve further attention:

Engaging vulnerable community stakeholders in medical research is less of a controlled and predictable science than we might wish. Nevertheless, it seems curious that we invest millions of dollars in product development, clinical training, design and building of facilities, etc., but often leave vital processes of community engagement largely to trial and error.

It seems as though $\mathrm{CE}$ is in danger of becoming a useless buzzword; the term is ambiguous and almost completely devoid of empirical evidence as to what works, in what contexts, and importantly, to what effects. Moreover, there are no agreed-upon ways to evaluate CE. Some biobankers may view their efforts as successful if they increase enrollment in the biobank. Others may feel that as long as their community of potential participants is not actively objecting to the biobank's activities, their CE efforts have succeeded. And yet, one of the purported benefits of conducting CE is increasing public trust in biobanking. With so many different notions of $\mathrm{CE}$, and no agreed-upon way to measure and evaluate efforts, public trust seems likely to erode over time.

\section{Limitations}

We acknowledge that this study has limitations in both the sample of respondents and potential for individual bias. Our sample size is small, the types of biobanks were heterogeneous, and within our sample, we interviewed people occupying different roles within each biobank. Thus, it may not be surprising that respondents'
Haldeman/Cadigan/Davis/Goldenberg/ Henderson/Lassiter/Reavely 
views of community and perceptions and practices of $\mathrm{CE}$ varied. Though we believe examining $\mathrm{CE}$ among a larger sample of biobankers is important, results from our recent survey of biobankers also reveal tremendous heterogeneity among biobanks' organizational characteristics and practices [2]. However, we believe that our respondents' varied responses to these issues also reflect the current state of the field of CE; that is, there is little guidance for biobanks on how to engage communities that is responsive to the heterogeneity of biobanks and virtually no discussion of how to define or measure successful CE efforts.

In order to address individual bias, as we have noted in our methods, our team of qualitative researchers met regularly upon completion of interviews to discuss responses and emergent themes. Discussion among researchers took place until consensus around patterns and themes of respondents was reached. In order to address interviewer bias, we selected short segments of a crosssection of interviews for all team members to analyze for codebook development and overall analysis.

\section{Conclusion}

Although there have been recent efforts to more clearly define practical steps for CE in clinical research, its meanings, practice and measures of success remain underexamined in biobanking $[15,25]$. In this study, biobank personnel reported that their bank conducted $\mathrm{CE}$ in order to build trust and relationships with specimen contributors, give back to those who participated, enhance recruitment, and for what they described as ethical reasons. CE efforts aimed at establishing trust were seen as part of improving recruitment to the biobanks we studied. According to our interviews, CE was primarily used to educate the community of potential participants and also to establish trust so that participants join or to enhance the chances of bank sustainability. Ultimately, more research is necessary to further explore and clarify the unique meanings of community within different biobanking contexts as well as varying biobank methods of $\mathrm{CE}$ and its benefits to the participants and the research enterprise. A better understanding of the various ways in which biobanks engage communities, and how those efforts impact those communities over time, may help those who wish to create new banks to consider their own relationships with potential participants and, thus, understand more fully what it means to be ethical.

\section{Acknowledgements}

We wish to thank the people who generously gave of their time and expertise to participate in these interviews. We also thank Robert Mitchell and Bryan Weiner for their assistance with the case studies. Funding for this project was provided through the following grants: 1R01HG005227-01A1 (G.E.H., PI, 'From Specimen to Biobank: Using An Organizational Perspective To Study ELSI Issues') from the NHGRI, and 5UL1RR025747-04S1, a supplement to U54RR024382-01A1 (M. Runge, PI, 'Enhancing Biobank Capacities Across CTSAs'). Support was also provided by the UNC Center for Genomics and Society, P50 HG004488 from the NHGRI. The content of this article does not necessarily reflect the views or policies of the funding agencies.

\section{References}

1 McCloskey DJ, McDonald MA, Cook J, Heurtin-Roberts S, Updegrove S, Sampson D, Gutter S, Eder M: Community engagement: definitions and organizing concepts from the literature. 2011. http://www.atsdr.cdc.gov/ communityengagement/pdf/PCE_Report_ Chapter_1_SHEF.pdf.

2 Henderson GE, Cadigan RJ, Edwards TP Conlon I, Nelson AG, Evans JP, Davis AM, Zimmer C, Weiner BJ: Characterizing biobank organizations in the U.S.: results from a national survey. Genome Med 2013;5:3.

3 Cornwall A, Jewkes R: What is participatory research ? Soc Sci Med 1995;41:1667-1676.

4 Shalowitz MU, Isacco A, Barquin N, ClarkKauffman E, Delger P, Nelson D, Quinn A, Wagenaar KA: Community-based participatory research: a review of the literature with strategies for community engagement. J Dev Behav Pediatr 2009;30:350-361.

5 Rowley D, Tosteson H: Racial differences in preterm delivery: developing a new research paradigm. New York, Oxford University Press, 1993.

-6 Israel BA, Schulz AJ, Parker EA, Becker AB: Review of community-based research: assessing partnership approaches to improve public health. Annu Rev Public Health 1998;19:173202.

7 Minkler M, Wallerstein N: The growing support for CBPR; in Minkler M, Wallerstein N (eds): Community-Based Participatory Research for Health: From Process to Outcomes, ed 2. San Francisco, Jossey-Bass, 2008.

8 Wallerstein N, Duran B: Community-based participatory research contributions to inter- vention research: the intersection of science and practice to improve health equity. Am J Public Health 2010;100(suppl 1):S40-S46.

9 Horowitz CR, Robinson M, Seifer S: Community-based participatory research from the margin to the mainstream: are researchers prepared? Circulation 2009;119:26332642.

10 Ahmed SM, Palermo AG: Community engagement in research: frameworks for education and peer review. Am J Public Health 2010;100:1380-1387.

11 Chung B, Jones L, Jones A, Corbett CE, Booker T, Wells KB, Collins B: Using community arts events to enhance collective efficacy and community engagement to address depression in an African American community. Am J Public Health 2009;99:237-244. 
12 Juengst ET: Community engagement in genetic research: the 'slow code' of research ethics?; in Knoppers BM (ed): Populations and Genetics: Legal and Socio-Ethical Perspectives. Leiden, Martinus Nijhoff Publishers, 2003, pp 181-198.

13 Anderson N, Bragg C, Hartzler A, Edwards K: Participant-centric initiatives: tools to facilitate engagement in research. Appl Transl Genomics 2012;1:25-29.

14 Ahmed SM, Palermo AG: Community engagement in research: frameworks for education and peer review. Am J Public Health 2010;100:1380-1387.

15 Isler MR, Corbie-Smith G: Practical steps to community engaged research: from inputs to outcomes. J Law Med Ethics 2012;40:904914.

16 Ross LF, Loup A, Nelson RM, Botkin JR, Kost R, Smith GR Jr, Gehlert S: Human subjects protections in community-engaged research: a research ethics framework. J Empir Res Hum Res Ethics 2010;5:5-17.

$\checkmark 17$ Beskow LM, Dean E: Informed consent for biorepositories: assessing prospective participants' understanding and opinions. Cancer Epidemiol Biomarkers Prev 2008;17:14401451.

18 Tindana PO, Rozmovits L, Boulanger RF, Bandewar SVS, Aborigo RA, Hodgson AVO, Kolopack P, Lavery JV: Aligning community engagement with traditional authority structures in global health research: a case study from northern Ghana. Am J Public Health 2011;101:1857-1867.

19 Lemke AA, Wu JT, Waudby C, Pulley J, Somkin CP, Trinidad SB: Community engagement in biobanking: experiences from the eMERGE Network. Genomics Soc Policy 2010;6:35-52.
20 Clayton EW, Smith M, Fullerton SM, Burke W, McCarty CA, Koenig BA, McGuire AL, Beskow LM, Dressler L, Lemke AA, Ramos EM, Rodriguez LL; Consent and Community Consultation Working Group of the eMERGE Consortium: Confronting real time ethical, legal, and social issues in the Electronic Medical Records and Genomics (eMERGE) Consortium. Genet Med 2010;12:616-620.

21 Godard B, Marshall J, Laberge C: Community engagement in genetic research: results of the first public consultation for the Quebec CARTaGENE project. Community Genet 2007;10:147-158.

22 Avard D, Knoppers BM: Genomic medicine: considerations for health professionals and the public. Genome Med 2009;1:25.

23 Tutton R: Constructing participation in genetic databases: citizenship, governance, and ambivalence. Sci Technol Hum Val 2007;32: 172-195.

24 Hewitt RE: Biobanking: the foundation of personalized medicine. Curr Opin Oncol 2011;23:112-119.

25 McCarty CA, Garber A, Reeser JC, Fost NC; Personalized Medicine Research Project Community Advisory Group and Ethics and Security Advisory Board: Study newsletters, community and ethics advisory boards, and focus group discussions provide ongoing feedback for a large biobank. 2011;155A:737741.

26 O’Doherty KC, Hawkins A: Structuring public engagement for effective input in policy development on human tissue biobanking. Public Health Genomics 2010;13:197-206.

27 McCarty CA, Chapman-Stone D, Derfus T, Giampietro PF, Fost N; Marshfield Clinic PMRP Community Advisory Group: Community consultation and communication for a population-based DNA biobank: the Marshfield clinic personalized medicine research project. Am J Med Genet A 2008;146A:30263033.
8 Ormond KE, Cirino AL, Helenowski IB, Chisholm RL, Wolf WA: Assessing the understanding of biobank participants. Am J Med Genet A 2009;149A:188-198.

29 Cadigan RJ, Lassiter D, Haldeman K, Conlon I, Reavely E, Henderson GE: Neglected ethical issues in biobank management: results from a U.S. Study. Life Sci Soc Policy 2013;9:1.

30 Lemke AA, Wolf WA, Hebert-Beirne J, Smith ME: Public and biobank participant attitudes toward genetic research participation and data sharing. Public Health Genomics 2010; 13:368-377.

31 Dickert N, Sugarman J: Ethical goals of community consultation in research. Am J Public Health 2005;95:1123-1127.

32 Newman PA: Towards a science of community engagement. Lancet 2006;367:302.

33 O'Doherty KC, Burgess MM, Edwards K, Gallagher RP, Hawkins AK, Kaye J, McCaffrey V, Winickoff DE: From consent to institutions: designing adaptive governance for genomic biobanks. Soc Sci Med 2011;73:367-374.

34 Knoppers BM: Populations and Genetics: Legal and Socio-Ethical Perspectives. Leiden, Martinus Nijhoff Publishers, 2003.

35 Brunger F: Problematizing the notion of 'community' in research ethics; in Knoppers BM (ed): Populations and Genetics: Legal and Socio-Ethical Perspectives. Leiden, Martinus Nijhoff Publishers, 2003, pp 245-256.

36 Weijer C: Philosophical and Pragmatic Challenges. Camb Q Healthc Ethics 1999;8:501513

37 Gbadegesin S, Wendler D: Protecting communities in health research from exploitation. Bioethics 2006;20:248-253.

38 Lidz CW, Simon LJ, Seligowski AV, Myers S, Gardner W, Candilis PJ, Arnold R, Appelbaum PS: The participation of community members on medical institutional review boards. J Empir Res Hum Res Ethics 2012;7: $1-6$ 